J. Lake Sci. (湖泊科学), $2006, \mathbf{1 8 ( 3 ) : 3 1 2 - 3 1 8 ~}$

http:// www. jlakes. org. E-mail: jlakes@ niglas. ac.cn

(c) 2006 by Journal of Lake Sciences

\title{
流域数据模型研究一一太湖流域西莒溪流域为例
}

\author{
高俊峰 $^{1}$, 问国年 ${ }^{2}$, 赵广举 $^{1}$, 李金莲 $^{1}$ \\ (1: 中国科学院南京地理与湖泊研究所,南京 210008) \\ (2: 南京师范大学,南京 210009)
}

摘 要: 流域数据模型是流域特征的语义、行为和规则的表达, 是进行集成流域模拟和管理的空间数据组织的重要内容. 本文以长江三角洲太湖流域上游的西苦溪流域为例, 将汇流单元分为自然流域、“大包围”、圩区三种形式, 分别建立了各 自内部的河湖网络关系, 即山区由自然流域单元, 内包含水库 (或湖泊)、河流、水工点的树状河湖网络关系; 平原区由人 工汇流单元, 内包含大包围、圩区、湖泊、湿地、河道、水工点的网状河湖网络关系,为建立适合我国的流域数据模型做了有 益的探索.

关键词:流域数据模型;汇流区;河湖网络;时间序列;西芳溪流域;太湖流域

\section{Watershed data model : a case study of Xitiaoxi sub-waterhed, Taihu Basin}

\author{
GAO Junfeng ${ }^{1}$, LU Guonian ${ }^{2}$, ZHAO Guangyu ${ }^{1} \&$ LI Jinlian ${ }^{1}$
}

(1:Nanjing Institute of Geography \& Limnology, CAS, Nanjing 210008, P. R. China)

(2:Nanjing Normal University, Nanjing 210009, P. R. China)

\begin{abstract}
Concept of watershed data model is from geodatabase. Watershed data model is the description of meaning, behavior and role of features in a watershed, which demanded by integrated watershed modeling and management. Taking the Xitiaoxi watershed, which is located in the upper reaches in Taihu Basin, as a case study, the drainage was divided into three types: watershed, flood control area and polder. Different stream-lake networks were constructed in these three drainage types: tree type stream-lake network, which include lake (reservoir), Dou, stream, hydrological points, in nature drainage (watershed); net type stream-lake network, which include flood control area, polder, lake, wetland, canal, stream and hydrological points, in artificial drainage. If the scale of drainage is selected suitably, any complex water network in the middle and lower reaches of the Yangzte River can be described by these two type stream-lake network. Features included in any of drainage type and relationships of each other were constructed in this paper, which can be helpful for watershed data model construction in China.
\end{abstract} Keywords: Watershed data model; drainage; stream-lake network; time series; Xitiaoxi watershed; Taihu Basin

流域数据模型是地理数据模型的一种, 它以流域过程模拟的需要来组织数据, 是流域模拟和管理必需 的空间数据的有效组织方式, 可以为流域模拟提供一致的语义、行为和规则. 流域模拟模型与流域数据模 型的区别在于: 流域模拟模型专注于过程的表达, 流域数据模型则侧重于空间和时间等流域数据类的属性 和关系的表达 ${ }^{[1]}$. 换句话说, 流域数据模型描述流域内各特征的位置、关系与类型; 流域模拟模型描述流域 特征在环境中的行为. 如何有效集成流域中各种复杂特征要素,并定义和组织它们之间的相互作用关系是 建立流域数据模型的关键.

目前我国的流域基础信息主要来源于国家基础地理信息库和水利部的水资源信息库,在表达流域内各 特征的相互关系方面存在不足,主要表现在两个方面,一是现有数据库的地理要素不包括流域水资源及水

* 江苏省自然科学基金(BK2005164)、中国科学院知识创新工程领域前沿重点项目 (CXNIGLAS - A01 - 1) 973 项 目 (2002CB412300) 联合资助. 2004-12-06 收稿;2005-07-06 收修改稿.

高俊峰,男,1967 年生, 博士, 副研究员; E-mail：gaojunf@ niglas. ac.cn. 
环境管理涉及的全部要素, 如土壤信息、土地利用信息及水环境信息; 二是现有数据库的组织和编码体系不 能满足流域管理涉及的众多过程分析的要求,最突出的是对流域特征之间的联系描述不够完善,如湖泊、台 站编码和流域、水系缺乏联系, 河流网络存在大量的断线及缺乏流向,不能合理表达流域特征. 国外比较成 功的流域数据库有美国的( NHD), 其采用 ESRI 公司的 Geodatabase 空间数据库概念.

我国的大河中下游地区,特别是长江流域的中下游, 人类活动对流域的自然状况影响强烈. 几千年的 人类活动已经改变了自然地理的景观和单元, 目前的格局是自然和人类活动综合作用的结果; 又因为地势 低洼, 水系结构极其复杂, 水流流向不定, 水系格局受工程的影响. 这些特点造成了这些地区流域数据模型 构造的复杂性, 而这些地区又是迫切需要深人研究的地区, 通过流域数据模型的构建, 以达到通用流域模拟 模型的构建和流域管理是目前急待解决的问题 ${ }^{[2]}$.

本文选择太湖流域的一个典型的子流域——西苕溪流域作为研究区, 以 Geodatabase 概念为基础, 构建 流域数据模型. 西苕溪流域具有长江中下游洪泛平原的各种流域特征:在汇流区类型上, 具有山区流域、平 原圩区、圢区、大包围等; 河湖网络特征上, 具有各种类型的水体、降雨响应单元、流域点特征、线特征和连接 关系, 是一个比较理想的研究区域.

\section{1 流域数据模型}

流域是一种完整的自然单元,其内部包括了各种自然的物理循环过程. 河流、湖泊、湿地、水库、洜站、 涵闸、堤坝等特征是流域的有机组成部分, 这些特征相互联系,相互作用,组成一个水系网络 ${ }^{[3]}$.

在流域数据模型中, “特征” (Feature) 指自然和人工形成的水结构体、水流路径以及相关实体 ${ }^{[4]}$. 特征 以点、线或面定义. 依据特征类型, 可以将特征分为:地形、河湖网络、水文响应单元、汇流区、河流、水文点、 河道、示意网络等.

\section{1 流域数据模型的逻辑关系}

流域数据模型由各种类型的汇流区 (流域) 和其内部的河湖网络关系组成. 水文响应单元则是模拟水 文过程的各个影响因素在网格单元的表示, 通常以栅格数据类型来表示 ${ }^{[5]}$.

汇流区包括自然的流域、“大包围” (洪涝控制线) 和圩区. 在每一类型里, 又有不同的河湖水系网络, 这些水系网络有的是在单元外,有的是在单元内. 通过水闸、洜站、子流域出口等将各个单元连接起来,水 系网络关系反映了水文系统的空间结构, 表达了水及以水为媒介的物质输移路径. 水文响应单元则是进行 水文过程模拟时各种汇流区内的与降雨 - 径流有关的要素离散为单元格的表示. 汇流区各特征之间的逻 辑关系如图 1 所示.

\section{2 汇流区}

水陆是相互作用的,一方面陆地的地貌和地形决定了水流的方向,另一方面流水的侵蚀又在塑造着陆 地. 一般来说, 流域是一个自然单元, 具有自然的边界和属性. 但在实际工作和管理过程中, 常常需要定义 一定区域作为流域. 如我国为了水资源管理和配置的需要,将全国划分为 10 个水资源分区,这些分区中, 有些一级区并不是自然流域边界,如西北诸河、西南诸河等区域就包括了诸多并不在一个自然流域内的几 个流域的集合. 这样的划分, 在水问题的研究, 如水资源配置、水质、洪涝预警, 以及其他公众或政府决策项 目带来方便.

为了表述的方便, 本文对流域这一概念定义为 “为特定目的分割的, 具有自然汇水边界的, 能够相互镶 嵌的自然单元”. 而汇流区定义为 “为流域管理目的而进行分割的, 行政上的管理区域”. 汇流区是指为流 域管理目的而进行分割的区域,可以是自然的流域,也可以是行政上的管理区. 当用“汇流区”时,一般指行 政上的管理区;当用“流域”时,一般指自然的流域单元.

汇流区 (流域) 又包括三种类型:子流域、大包围与圩区. 子流域是指为研究和管理的方便,将一个大的 流域划分为若干小块,每一个小块可以称为一个 “子流域”. 子流域是可以分级的,如流域下可以包括一级 子流域,一级子流域下面还可以包括二级子流域, 以此类推. 一般来说子流域的级别是根据河流的级别来 确定的,如一级河流的集水区可以称为一级子流域,二级河流的集水区可以称为二级子流域. 但有时为了 研究的方便,往往根据需要自行确定 (图 $2: a$ ). 


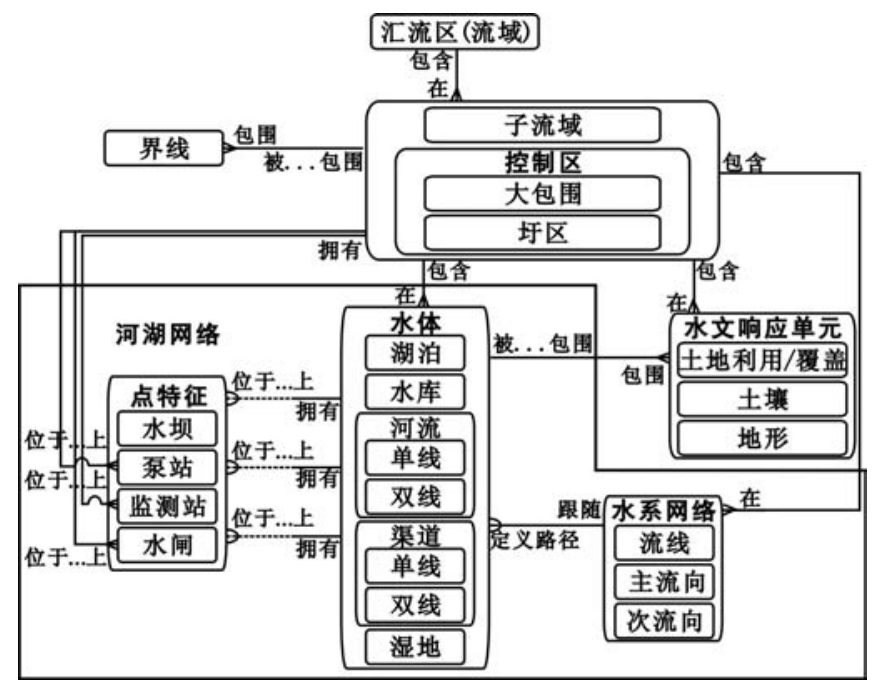

图 1 流域数据模型的逻辑关系

Fig. 1 Logical relationship of watershed data model

大包围是洪泛平原特有的一种由水利工程控制的区域. 为了防洪的需要,在特定区域的主要河流上建 控制闸和排涝站, 以控制区域外的洪水进人,排空区域内的洪涝. 这种形式在太湖流域的下游更常见, 规模 也更大. 图 2(b) 显示了大包围示意图. 在太湖流域, 大包围规模要小于三级子流域, 但有些大包围就是四 级子流域. 子流域所拥有的特征和关系,大包围也拥有.

圩区是人们沿着低洼地区的河道修筑堤坝,将特定的区域与外界围隔开来,被围隔区域内的河流通过 闸门和洜站实现与区域外河流的水量交换 ${ }^{[6]}$ (图 $2: \mathrm{c}$ ). 圩区一般分布在低洼平原区,圩内高差一般在 $2 \mathrm{~m}$ 以内,圩内水网密集, 分布有池塘. 在我国长江中游地区, 这种单元又叫“堤垸”、“垸”.

㘰是圩区的一种特殊形式,在低洼沿河的一面修筑圩堤,在高处与山脊线相联形成一个汇流区 ${ }^{[6]}$ (图 2:d). 一般分布在山前平坦低洼区. 㘰内的高差一般较大, 可达几十米甚至上百米, 与圩区类似, 在低洼的 一边也有泵站和水闸控制内水量与外河的交换.

\section{3 河湖网络关系}

河流是一系列从源头到河口, 按照顺序连接的水流通道, 可以表示为单线 (线状) 和双线 (面状). 水体 是流域内以面状的表示的储水体, 如双线河、水库、湖泊、湿地 (沼泽) 等. 水工点是流域内以点表示的水文 信息,如水闸、水坝、水文观测点等. 由这三类特征形成了现实世界中复杂的河湖网络关系.

河湖网络关系包括二种:一种是现实世界中存在的、主要的河湖网络关系,它表示了流域内点、线和面 特征之间的连接和拓扑关系; 一种是现实世界中不存在的,但在流域模拟计算中需要的一种关系,即示意性 网络关系. 本文主要讨论前一种关系.

概括现实流域中河湖特征的网络关系, 可以分为以下 5 种:

1) 点 - 线关系: 这种关系在河湖网络中表示点特征位于线特征之上. 如水坝位于水库之上,监测站位 于河流之上,水闸位于渠道之上; 从线特征角度说, 就是 “线特征拥有点特征”, 如渠道拥有水闸, 河流拥有 泵站等等.

2) 点 - 面关系: 这种关系在河湖网络中表示点特征位于面特征之上和点特征位于面特征里. 前者表示 的实体关系如洜站位于双线河流之上,水闸位于双线渠道之上等关系; 点位于面之里表示的实体关系如监 测站位于子流域里, 水闸位于圩区里, 泵站位于大包围里等关系. 从另一方面来说, 也可以说河流拥有洜 站,子流域包含监测站.

3 ) 线 - 线关系:这种关系在河湖网络中表示线特征跟随线特征,或者是线特征与线特征 “咬合”. 前者 


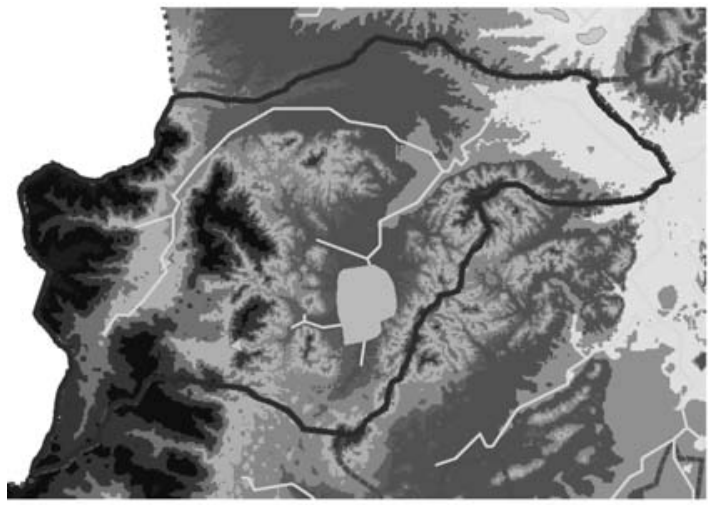

(a)

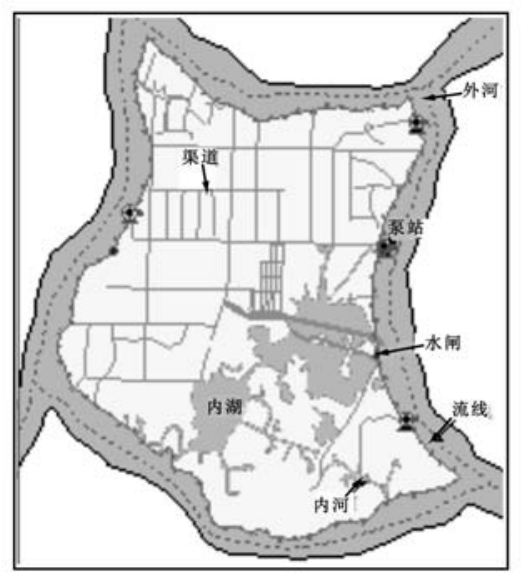

(c)

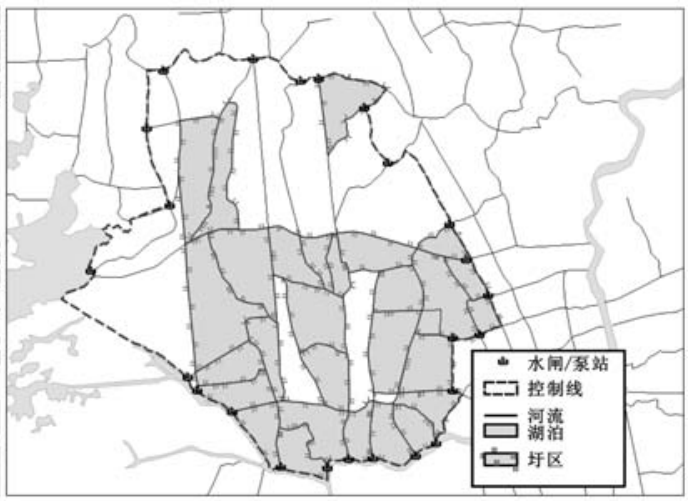

(b)

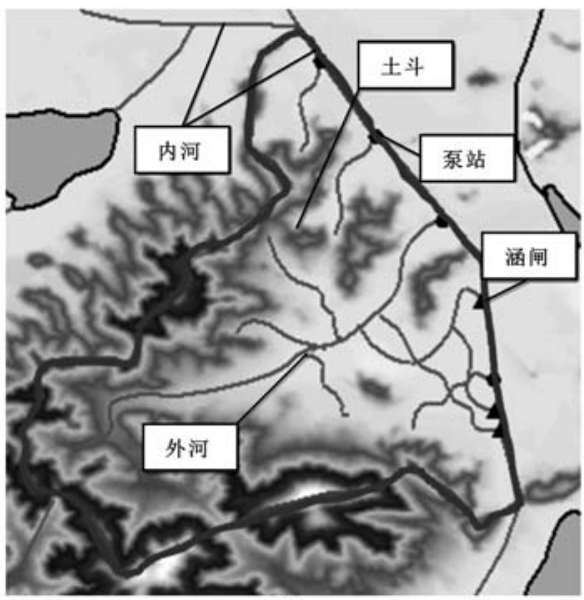

(d)

图 2 汇流区 (流域) 单元类型 $(\mathrm{a}$ : 子流域; $\mathrm{b}$ :大包围; $\mathrm{c}$ :圩区; $\mathrm{d}:$ 圢)

Fig. 2 Watershed type (a: sub-watershed; b: flood control area; c: polder; d: Dou)

如流线跟随单线河 (渠道) (即与单线河重合),一旦单线河消失, 流线也不存在; 后者如单线河与单线河在 节点处咬合连接在一起.

4) 线 - 面关系:这种关系在河湖网络中表示线特征跟随面特征、线特征包围面特征,或线特征与面特 征相邻的关系. 线特征跟随面特征, 如流线跟随双线河 (渠道), 流线跟随湖泊 (水库); 线特征包含面特征, 如流域边界线包围流域,水体边界线包围水体;线特征与面特征相邻,如圩区边界与外河相邻. 从另一方面 来说,也可以说双线河流(渠道)定义流线的路径,流域被边界线包围.

5) 面 - 面关系:这种关系在河湖网络中表示包含、相邻和被包含的关系. 如湖泊在子流域里 (子流域包 含湖泊), 圩区在大包围里 (大包围包含圩区) ; 相邻关系表达面特征之间没有重叠, 没有裂缝, 如子流域之 间不能重叠,也不能有裂缝.

由这些网络关系组成了两大类型的河湖网络关系: 即山区由自然流域单元, 内包含水库 (或湖泊)、河 流、水工点的树状河湖网络关系 (图 $3: a$ ) ; 平原区由人工汇流单元, 内包含大包围、圩区、湖泊、湿地、河道、 水工点的网状河湖网络关系 (图 3:b、c). 任何复杂的河湖网络, 如果尺度分得足够小, 总可以以某种汇流 区 (子流域、大包围、圩区) 来表示,内部的河湖网络关系总可以以这两种关系来概括.

当单元的尺度划分得足够小,则河湖网络关系出现复杂的形态. 如圩区的河湖网络关系 (图 2 : c ; 图 3: c) 由内部和外部两大部分组成. 内部包括了自然河道和人工渠道、内部湖泊、水闸、洜站,同时通过水闸和 
泵站实现与外部水系网络的水量交换. 作为一个人工汇流单元, 其外部有更大的河流包围, 与外部的河流、 湖泊、洜站、水闸等构成了大包围内部的河湖网络关系 (图 $2: b$; 图 $3: b$ ). 大包围外部有更大的骨干河流, 与 湖泊、控制站、水闸、泵站等组成汇流单元.

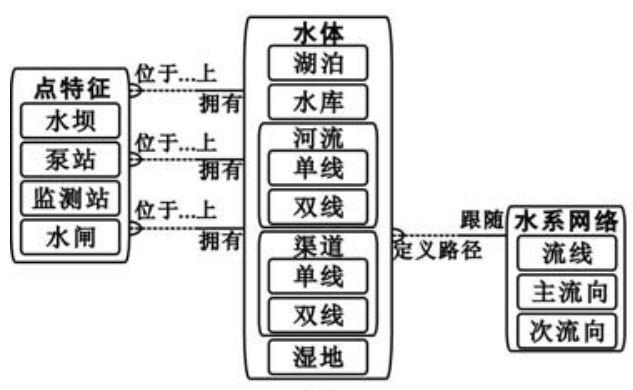

(a)

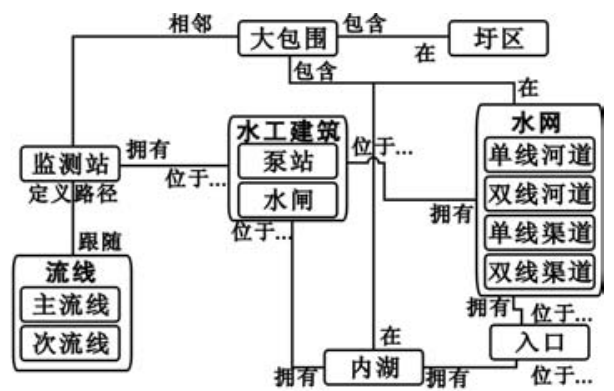

(b)

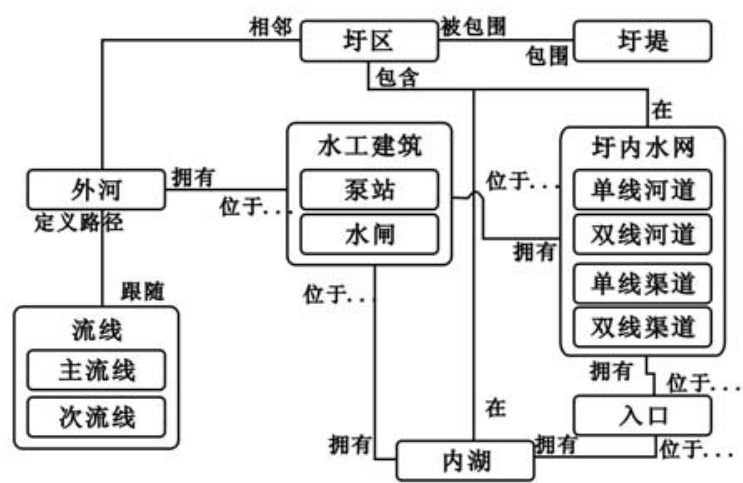

(c)

图 3 各种类型汇流区内的河湖网络关系 (a: 子流域; :大包围; $\mathrm{c}$ : 圩区)

Fig. 3 Water system relationship in different watershed type

( a: sub-watershed; b: flood control area; c: polder (Dou))

\section{4 时间序列}

时间序列 (Time Series) 用来描述流域内随时间变化的特征数据 ${ }^{[7]}$. 河流流过陆地, 降雨 - 径流汇集到 河网,下游河网的水量逐渐增加,这些过程都随时间而变化.

在水文过程模拟中,降雨、蒸发、温度等都是随时变化的时间序列数据. 时间序列数据常常数据量很 大, 可能包括数十年的每天或小时的数据, 并且时间间隔也不尽相同, 可能是月平均、旬平均、日平均, 或 6 小时、小时数据. 最普通的时间序列数据是包括时间和观测值的、以表格记录的观测数据.

时间序列有三个方面的内容:空间、时间和类型的分类. 空间位置由与时间序列相联系的地理位置决 定,如河流上某一位置的水位或流量观测站; 时间位置由观测现象的时间标记决定;一个特征可能与一系列 不同的时间序列关联,如一个水文观测站可能同时观测降雨、蒸发、流量、水位、水温等.

当时间序列与一个地理特征相联系时, 可以将其看作地理特征的属性信息. 当一个类中所有的特征拥 有了给定属性的时间序列数据, 这个序列就可以称为属性序列.

\section{2 实例一一西莟溪流域数据模型}

\section{1 试验区位置与数据来源}

研究区西莒溪流域位于长江三角洲的太湖流域的上游, 地理坐标在 $30^{\circ} 22^{\prime}-30^{\circ} 57^{\prime} \mathrm{N} 、 119^{\circ} 14^{\prime}-120^{\circ} 8^{\prime}$ $\mathrm{E}$ 之间, 流域土地面积 $2271 \mathrm{~km}^{2}$, 行政隶属于浙江和安徽省,包括湖州市安吉县、长兴县、湖州市区及安徽省 
一部分. 西苕溪流域地形由南向东倾斜,南部高, 北部低. 地形可分为三种类型 : 南部和东北部高山和低山 区, 中部丘陵区和北部低洼平原区. 高程在 $150 \mathrm{~m}$ 以下部分占流域面积的 $48.01 \%, 150-600 \mathrm{~m}$ 部分占 $39.31 \%$,这二部分占到流域面积的 $87.32 \%$,高山部分仅占流域面积的 $12.68 \%$.

西苕溪数据模型的数据来源见表 1 所示.

表 1 西苕溪流域数据模型的数据来源

Tab. 1 Data sources of Xitiaoxi watershed data model

\begin{tabular}{cccc}
\hline 特征名称 & 比例尺 & 特征类型 & 来源 \\
\hline 水系 & $1: 50000$ & 线、面 & 地形图数字化 \\
水体 & $1: 50000$ & 面 & 地形图数字化 \\
流域界线 & $1: 50000$ & 面、线 & 水利分区图数字化 \\
大包围、圩区 & $1: 55000$ & 面 & 水利图数字化 \\
泵站、水闸、水坝 & $1: 55000$ & 点 & 水利图数字化 \\
土地利用 & $1: 50000$ & 面 & 国土局 \\
DEM & $1: 50000$ & 栅格 & 基础地理信息中心 \\
水文站位置 & & 点 & 水利局 \\
\hline
\end{tabular}

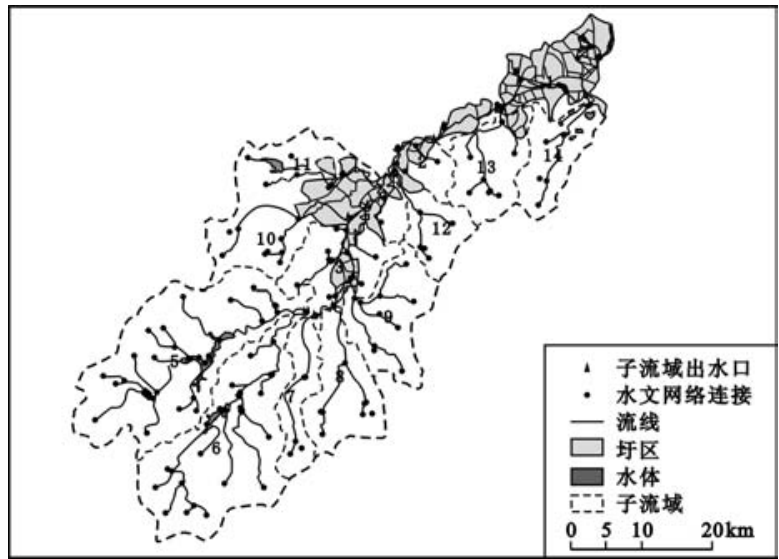

图 4 西苕溪数据模型结果图

Fig. 4 Sample watershed data model of Xitiaoxi watershed

\section{2 结果}

根据以上所述流域数据模型和数据源, 采用 Arc Hydro 分析工具建立流域水系的空间网络联系和水力 联系, 并将监测数据的时间序列集成到流域数据库中 ${ }^{[8]}$. 图 4 所示为西苕溪流域的数据模型. 其中山区河 流自动生成, 平原区 (高程在 $100 \mathrm{~m}$ 以下, 坡度小于 $30^{\circ}$ ) 水网由地形图数字化而得, 并与自动生成河网结 合, 详细介绍见参考文献 ${ }^{[9]}$, 在此不做赘述. 子流域的大小根据水文模拟的需要人为确定为 13 个, 将上游 水库和自然子流域,中游的丘陵区和下游的低洼平原区分别划人不同的子流域. 圩(㘰)区分别划人不同的 子流域,其中子流域编号 $9 、 10 、 13 、 14$ 的下游分布有㘰; 子流域编号 11 下游上部分布有㘰, 下部分布有圩; 子流域编号 $1 、 2 、 3$ 是西苕溪流域干流流经的下游和中游平坦地区,分布有圩区. 圩和㘰内部还有复杂的水 系, 由于比例尺所限,没有标出. 西苕溪流域没有“大包围”, 但这种形式在太湖流域的下游很普遍. 


\section{3 结论与讨论}

本研究将研究区西苕溪流域汇流单元分为自然流域、大包围、圩区三种形式, 所建立的西苕溪流域流域 数据模型有以下特点:一是流域数据模型中集成了流域的基本要素; 二是分别建立了各自内部的河湖网络 关系, 即山区由自然流域单元, 内包含水库 (或湖泊)、河流、水工点的树状河湖网络关系; 平原区由人工汇 流单元, 内包含大包围、圩区、湖泊、湿地、河道、水工点的网状河湖网络关系; 三是实现了空间信息和要素状 态时间序列的一体化表达. 为建立适合我国的流域数据模型做了有益的探索.

流域数据模型的建立是一件十分困难和工程浩大的事情. 困难在于流域的复杂性和差异性, 与流域过 程相关的因素非常多, 各种关系错综复杂, 分析、描述这些关系难度较大. 另外, 流域之间的内部状况差别 很大, 流域数据模型需要根据具体流域所面临的实际问题进行设计. 尽管可以建立通用的流域数据模型概 念, 但在实际流域数据模型的建立过程中可操作性比较差, 需要就具体情况进行具体分析. 数据模型建立 也是一件十分耗时费力的工作, 具体工作包括基础数据的准备、分析、编码、分类、建立各种关系等等. 因为 我国目前数据共享状况不理想, 也增加了实际工作的难度.

\section{4 参考文献}

[1] Maidment DR ed. Arc hydro: GIS for water resources. United States: ESRI Press,2002.

[2] 李恒鹏,刘晓玫,李金莲. 采用 Geodatabase 技术构建流域水文系统地理数据库. 湖泊科学, 2005,17 (3) : $275-281$.

[3] Westervelt J. Simulation modeling for watershed management. New York: Spring-Verlag Inc,2001.

[4] 高俊峰, 问国年, 刘晓玫,何宝金. 基于地理数据库模型的流域数据模型设计. 现代测绘, 2004,27(5): $18-20$.

[5] 王中根, 刘昌明, 吴险峰. 基于 DEM 的分布式水文模型研究综上所述述. 自然资源学报, 2003,18(2): $168-173$.

[6] 高俊峰,毛 锐. 太湖地区圩区分类及圩区洪涝分析一以湖西区为例. 湖泊科学, 1993,5(4):307 -314 .

[7] 陈 华, 郭生练, 熊立华等. 面向对像的 GIS 水文资源数据模型设计与实现. 水科学进展, 2005, 16 (4) :556-563.

[8] Zeiler M. Modeling our world. New York: ESRI Press, 1999.

[9] 李昌峰, 冯学智, 赵 锐. 流域水系自动提取的方法和应用. 湖泊科学, 2003, 15(3): 205-212. 